\title{
Cost is an ethical issue
}

\author{
Fiona Godlee editor, BMJ
}

\begin{abstract}
Money is tight, so getting value for money has to be a top priority for all of us in healthcare. As Jim Easton, the man in charge of improvement and efficiency for the NHS, says whenever he speaks, cost is an ethical issue. Why, then, do we have so little information on cost effectiveness?
\end{abstract}

Teppo Järvinen and colleagues find this especially worrying in the case of drug treatments for prevention (doi:10.1136/bmj. $\mathrm{d} 2175)$. They say that for major preventive drugs, such as statins, antihypertensives, and bisphosphonates, there are "no valid data" on effectiveness or cost effectiveness. This may come as a surprise to some of you. It did to me. They explain that claims for the cost effectiveness of these and other drugs are based on efficacy data from randomised trials in idealised populations. In the real world of clinical care, true cost effectiveness may be much lower. Malcolm Willett's cartoon shows a man standing on the bottom "efficacy" rung of a ladder: "This is fine," he says. "I can see all the evidence I need from here."

What Järvinen and colleagues urge us to recognise is that we can't. To really see whether these drugs represent value for money, we need to take two steps up. We need to understand effectiveness and cost effectiveness in real clinical settings. As an example of how to do this, they refer to a 2001 study by Clare Robertson and colleagues (BMJ 2001;322:701, doi:10. 1136/bmj.322.7288.701). But they point out that this assessed a non-drug intervention-exercise for preventing falls in older adults. "We wonder at the virtual absence of empirical cost effectiveness data on preventive drugs when drug companies stand to make millions of profit a week if their drugs are shown to reduce important clinical outcomes in the community setting."

The $B M J$ has a longstanding policy of publishing cost effectiveness studies alongside or after randomised trials and systematic reviews. This week we apply the policy to the challenge of how best to treat heavy menstrual bleeding. A systematic review and individual patient data meta-analysis published last year found that hysterectomy scores higher (least dissatisfaction among patients) than endometrial ablation or the Mirena coil (BMJ 2010;341:c3929, doi:10.1136/bmj.c3929). Now the same group has done a full cost effectiveness analysis (doi:10.1136/bmj.d2202) and concludes that hysterectomy is likely to be the most cost effective strategy. NICE guidelines currently favour Mirena.

At least we do have NICE. With all its inevitable imperfections, it's still a national treasure. Spare a thought for those charged with creating something similar in the United States, where the C word can't be mentioned. Instead of "cost," the focus is firmly on comparative effectiveness in the form of head to head comparisons. And even then, as Doug Kamerow reports (doi:10. 1136/bmj.d2635), the Wall Street Journal snipes “Comparative effectiveness isn't about informing choices, it's about taking away options." But there's no alternative to comparing one treatment with another if we are to make rational decisions; and whatever your health system, cost is an ethical issue.

Cite this as: $B M J 2011 ; 342: \mathrm{d} 2813$ 